\title{
Out of hospital cardiac arrest survivors with inconclusive coronary angiogram: impact of cardiovascular magnetic resonance on clinical management and decision-making
}

\author{
Anna Baritussio ${ }^{1,2^{*}}$, Martina Perazzolo Marra², Amardeep Ghosh Dastidar ${ }^{1}$, Jonathan Rodrigues ${ }^{1}$, Alessandro Zorzi ${ }^{2}$, \\ Angela Susana ${ }^{2}$, Alessandra Scatteia ${ }^{1}$, Estefania De Garate ${ }^{1}$, Giulia Mattesi ${ }^{2}$, Julian Strange ${ }^{1}$, Domenico Corrado ${ }^{2}$, \\ Chiara Bucciarelli-Ducci ${ }^{1}$
}

From 19th Annual SCMR Scientific Sessions

Los Angeles, CA, USA. 27-30 January 2016

\begin{abstract}
Background
Non-traumatic out of hospital cardiac arrest (OHCA) is the leading cause of death worldwide, acute coronary syndromes accounting for up to $2 / 3$ of cases. Urgent angiography with a view to primary percutaneous coronary intervention (PPCI) is a class IB recommendation according to international guidelines. Diagnosis and management of patients with unobstructed coronaries or unidentified culprit lesion on angiogram is challenging. Cardiac magnetic resonance (CMR) with its superior tissue characterization is a well-established diagnostic technique. We sought to assess the additive role of CMR in diagnosis and management of patients with an inconclusive coronary angiogram and to determine which findings on CMR best predict clinical impact.
\end{abstract}

\section{Methods}

We retrospectively analysed our database to collect data on consecutive patients surviving non-traumatic OHCA, undergoing urgent coronary angiogram and CMR. We focused the analysis on patients with an inconclusive angiogram, defined as the evidence of unobstructed coronaries or of coronary artery disease (CAD) without a clear culprit lesion. Clinical impact of CMR was defined as a change in diagnosis, as compared to that made on a multiparametric pre-CMR basis (clinical history, electrocardiogram, trans-thoracic echocardiogram), or a change in management, which could be a change in medication or the performance/avoidance of invasive procedures (repeat angiogram, myocardial revascularization, ICD implantation).

\section{Results}

Out of 157 patients surviving OHCA referred for CMR after urgent angiogram, we identified 104 patients $(78 \%$ male, mean age $55.4 \pm 16.7)$ with inconclusive angiogram (66\%): 67 patients (64\%) had unobstructed coronaries and 37 (36\%) had CAD with no clear culprit. Diagnosis based on CMR findings was ischemic heart disease in 42 patients (40\%), non-ischemic heart disease in $30(29 \%)$, a structurally normal heart was found in 25 patients $(24 \%)$ and non-specific findings in 7 (7\%). Overall, CMR had a clinical impact in 68/104 patients (65\%), determining a change in diagnosis in $17 \%$ of patients, a change in management in $31 \%$ and both a change in diagnosis and management in $17 \%$. CMR led to myocardial revascularization in $18 \%$ of patients and to ICD implantation in $16 \%$; based on CMR findings, an invasive procedure was avoided in $17 \%$ of patients. In a multivariate model that included clinical and imaging parameters, LGE (p 0.049, 95\% CI 0.09-0.99) and segmental regional wall motion abnormality (p 0.018, 95\% CI 1.31-18.9) were the strongest independent predictors of CMR clinical impact (Table 1). 
Table 1 Predictors of clinical impact

\begin{tabular}{ccccc}
\hline & Sig. & Exp (B) & \multicolumn{2}{c}{ 95\% Cl for EXP (B) } \\
\hline Age & & & Lower & Upper \\
\hline Gender & 0.056 & 1.030 & 0.999 & 1.062 \\
LVEF & 0.759 & 0.834 & 0.262 & 2.654 \\
LViEDV & 0.857 & 0.996 & 0.948 & 1.045 \\
LGE & 0.513 & 1.008 & 0.985 & 1.031 \\
Segmental RWMA & 0.049 & 0.313 & 0.098 & 0.994 \\
Global RWMA & 0.018 & 4.985 & 1.312 & 18.936 \\
Impact of STIR & 0.142 & 1.532 & 0.294 & 7.976 \\
\hline
\end{tabular}

LVEF, left ventricular ejection fraction; LViEDV, left ventricular indexed enddiastolic volume; LGE, late gadolinium enhancement; RWMA, regional wall motion abnormality; STIR, short-tau inversion recovery

\section{Conclusions}

CMR had an additive clinical impact on diagnosis and management in $65 \%$ of patients surviving OHCA with an inconclusive coronary angiogram. LGE and segmental regional wall motion abnormality were the best independent predictors of clinical impact following CMR. CMR should be enclosed in the clinical-diagnostic work-up of this subgroup of OHCA survivors.

\section{Authors' details}

${ }^{1}$ Bristol NIHR Cardiovascular Biomedical Research Unit, Bristol Heart Institute, Bristol, UK. ${ }^{2}$ Department of Cardiac, Thoracic and Vascular Sciences, University of Padua, Padua, Italy.

Published: 27 January 2016

doi:10.1186/1532-429X-18-S1-062

Cite this article as: Baritussio et al:: Out of hospital cardiac arrest survivors with inconclusive coronary angiogram: impact of cardiovascular magnetic resonance on clinical management and decision-making. Journal of Cardiovascular Magnetic Resonance 201618 (Suppl 1):O62.

Submit your next manuscript to BioMed Central and take full advantage of:

- Convenient online submission

- Thorough peer review

- No space constraints or color figure charges

- Immediate publication on acceptance

- Inclusion in PubMed, CAS, Scopus and Google Scholar

- Research which is freely available for redistribution

Submit your manuscript at www.biomedcentral.com/submit 